\title{
Modulatory Effects of Vitamin C and E on Cypermethrin-Induced Cardiac and Hepatic Damage in Female Wistar Rats
}

\author{
Oladele $\mathrm{JO}^{1,3}$, Adewale $\mathrm{OO}^{2}$, Oyewole $\mathrm{OI}^{1 *}$, Oyeleke $\mathrm{OM}^{3}$, Ilori $\mathrm{OT}^{1}$, and \\ Olayinka $\mathrm{OE}^{1}$ \\ ${ }^{1}$ Phytomedicine and Toxicology Laboratories, Department of Biochemistry, Faculty of Basic \\ and Applied Sciences, Osun State University, Osogbo, Nigeria \\ ${ }^{2}$ Cancer Research and Molecular Toxicology Laboratories, Department of Biochemistry, \\ Faculty of Basic and Applied Sciences, Osun State University, Osogbo, Nigeria \\ ${ }^{3}$ Biochemistry Unit, Department of Chemical Sciences, Faculty of Sciences, Kings University, \\ Ode-Omu, Nigeria
}

Research Article

Volume 5 Issue 1

Received Date: March 06, 2020

Published Date: March 25, 2020

DOI: $10.23880 /$ act- 16000182

*Corresponding author: Oyewole OI, Phytomedicine and Toxicology Laboratories, Department of Biochemistry, Faculty of Basic and Applied Sciences, Osun State University, Osogbo, Nigeria; E-mail: ioluoye@yahoo.com., jo.oladele@kingsuniversity.edu.ng

\section{Abstract}

The rationale behind this study was to determine the possible ameliorating effect of Vitamin C and E on Cypermethrin induced toxicity in heart and liver function of female albino rats. Twenty-eight female albino rats were sorted into four groups of seven rats per groups were used in this study. Group A serves as the control and received distilled water orally. Group B, C and D were administered $25 \mathrm{mg} / \mathrm{kg}$ body weight cypermethrin orally. Group C and D were treated daily with $40 \mathrm{mg} / \mathrm{kg}$ body weight vitamin $\mathrm{C}$ and $20 \mathrm{mg} / \mathrm{kg}$ body weight vitamin E respectively by oral administration while group B was left untreated for 14 days. Cypermethrin significantly $(\mathrm{P}<0.05)$ induced cardiac and hepatic damage as characterized by elevated levels of serum alanine aminotransferase (ALT), aspartate aminotransferase (AST), hepatic bilirubin and decrease in cardiac albumin, globulin, total protein, ALP, LDH and GGT. However, treatment with vitamin C and E significantly ameliorate the adverse effects of Cypermethrin. Histological examination of the cadiac and hepatic tissues correlates with the biochemical results indicating marked distortions in the architecture of heart and liver of rats administered Cypermethrin alone but treatment with vitamin $\mathrm{C}$ and $\mathrm{E}$ attenuated these alterations. In conclusion, vitamin $\mathrm{C}$ and $\mathrm{E}$ effectively suppress the toxicity effects of Cypermethrin in heart and liver of rats by scavenging the free radicals and protecting the membrane integrity of the tissues.

Keywords: Cypermethrin; Vitamins; Transferase; Cardiac Damage; Hepatic Damage

\section{Introduction}

The deleterious effect of agrochemicals and pollutants has its impact on all living organism. The water pollutants include industrial, agricultural and urban discharges that have hazardous effect on aquatic organisms especially when these contaminants are slight decomposers and exhibit high potential for accumulation with synergistic effect [1]. Cypermethrin has become one of the most important insecticides in wide scale use. It has wide uses in cotton, cereals, vegetables and fruit, for food storage, in public health and in animal husbandry.

Cypermethrin, an analogue of pyrethrins is classified by the World Health Organization (WHO) as moderately hazardous (class II). It interacts with the sodium channels in nerve cells through which sodium enters the cell in order to transmit a nerve signal. These channels can remain open for up to seconds compared to the normal period of a few milliseconds, after a signal has been transmitted 
[2]. Cypermethrin also interferes with other receptors in the nervous system. The effect is that of long lasting trains of repetitive impulses in sense organ [3]. Also, Oladele et al (2020) reported that exposure of cypermethrin to experimental rats caused renal dysfunction and electrolyte imbalance in the rats.

Antioxidants(likevitamins, polyphenols, phytochemicals, lipoic acid, etc) are employed as nutrient supplementation in clinical interventions and are being extensively used by people with differential types of pathological disorders in order to partially treat, inhibit or slow down the deleterious effects of these disorders. Vitamin $\mathrm{E}$ is such naturally occurring, lipid soluble, chain breaking antioxidant in biological membranes [4]. Vitamin $\mathrm{E}$ is an effective free radical scavenger in the brain. Experimental studies have showed that vitamin E prevented neuronal damage from reactive NO species and was found to play an important role in neurodegenerative diseases related to oxidative stress $[5,6]$. The other important functions of these vitamins have been suggested to be in cell signaling. As an antioxidant, vitamin $E$ acts as a peroxyl radical scavenger, preventing the propagation of free radicals in tissues, by reacting with them to form a tocopheryl radical, which will then be reduced by a hydrogen donor (such as vitamin C) and thus return to its reduced state [7]. Based on this background this study was designed to investigate the ability of this vitamins to mitigate the toxic effect of Cypermethrin in heart and liver of wistar rats.

\section{Materials and Method}

\section{Chemicals/Reagents}

Cypermethrin [Cyano-(3-phenoxyphenylmethyl) 3-(2,2-dimethylclopropane-1-carboxylate] is obtained as Cypeforce, a product of Gharda Chemicals limited India, Vitamin C is obtained from Jinling pharmaceuticals, Vitamin $\mathrm{E}$ is a product of Embassy pharmaceuticals, albumin, total protein, bilirubin, alanine amino transferase and aspartate amino tranferase assay kits are products of Randox Chemical limited, England. All other chemicals are of analytical grade and were obtained from Analar BDH Limited, Poole, England.

\section{Experimental Protocol}

This study was performed with twenty-eight female albino rats (average weights 150-160g) obtained from the Department of Anatomy, University of Ibadan and were housed in ventilated cages in the Animal house of Biochemistry Department, Osun State University, Osogbo, Nigeria. The rats were acclimatized for 3 weeks before administration of the drugs. The experiment was carried out in accordance to current rules and guidelines that have been established for the care of the laboratory animals [8].
The animals were divided into four groups of seven rats per groups. Group A serves as the control and received distilled water orally. Group B, C and D were administered $25 \mathrm{mg} / \mathrm{kg}$ body weight cypermethrin orally. Group C and D were treated daily with $40 \mathrm{mg} / \mathrm{kg}$ body weight vitamin $\mathrm{C}$ and $20 \mathrm{mg} / \mathrm{kg}$ body weight vitamin E respectively by oral administration while group B was left untreated. Animals were kept at optimum temperature with a 12 hours light/ dark cycle and given rat feed in form of pellet and water ad libitum. The cages were cleaned twice daily. The period of administration lasted for 14 days.

\section{Preparation of Serum}

The rats were sacrificed $24 \mathrm{hrs}$ after the last treatment by cervical dislocation. The jugular vein was cut and blood sample collected into clean, dry centrifuge tube. The blood was left for $10 \mathrm{~min}$ at room temperature to clot after which it was centrifuged at 4,000 rpm in an MSC (Essex, UK) bench centrifuge. The clear supernatant (serum) was aspirated using a Pasteur pipette into clean, dry sample bottles and then stored at $-4^{\circ} \mathrm{C}$ for biochemical analyses.

\section{Preparation of Tissue Homogenates}

The heart and liver were quickly excised from the rat and immediately placed on a blotting paper to remove blood stains. The tissues were then rinsed in $1.15 \% \mathrm{KCl}$ to remove haemoglobin followed by homogenization in 4 volumes of ice-cold $0.01 \mathrm{M}$ potassium phosphate buffer ( $\mathrm{pH}$ 7.4) using Teflon homogenizer. The homogenates were centrifuged at $12,500 \mathrm{~g}$ for $20 \mathrm{~min}$ at $4^{\circ} \mathrm{C}$ to obtain supernatants (postmitochondrial fractions) which were stored till required for assay.

\section{Determination of Biochemical Parameters}

Colorimetric determination of protein concentration was done using bovine serum albumin as standard [9] while globulin was estimated using the method of Mokady, et al. [10]. Albumin concentration in the serum was measured using the bromocrecsol green method [11]. Serum ALT and AST activities were determined using based on the principle described by Reitman and Frankel [12]. Alkaline phosphatase (ALP) was measured by the method of Wright, et al [13], Lactate dehydrogenase (LDH) was measured by method of Vanderlinde [14]. Bilirubin and GGT were measuring based on the instruction of the manufacturer (randox) kit.

\section{Histological Examination}

The heart and liver were fixed in $10 \%$ formalin and embedded in paraffin wax. Thin sections (7-9 mm thickness) of the tissues were cut and dewaxed in xylene, hydrated in decreasing percentage of alcohol and stained 
with hematoxylin. They were then dehydrated in increasing percentage of alcohols till $70 \%$ and stained with $1 \%$ alcoholic eosin. They were differentiated in $90 \%$ alcohol and cleared in xylene. These stained sections were observed under the microscope for histopathological analysis.

\section{Statistical Analysis}

Results obtained were expressed as mean value \pm standard deviation (SD). Comparison was done using oneway analysis of variance (ANOVA) between the control and treatment groups. $\mathrm{P}$ values $<0.05$ were considered statistically significant.

\section{Results}

The effect of vitamin $C$ and $E$ on cypermethrin -induced changes in cardiac albumin, globulin and total protein concentrations in female wistar rats

Cypermethrin induced significant reduction in cardiac albumin, globulin and total protein concentrations in the exposed rats when compared to control, individual administration of vitamins $\mathrm{C}$ and $\mathrm{E}$ significantly raised the concentration of these parameters (Figure 1).

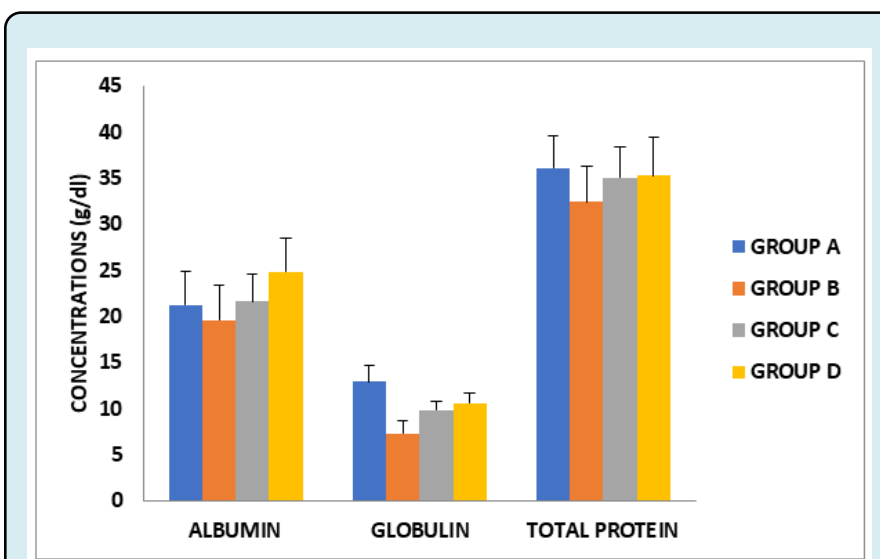

Figure 1: The effect of administration of vitamin $C$ and E on cypermethrin -induced changes in cardiac albumin, globulin and total protein in female wistar rats.

Values are means \pm SD

The effect of administration of vitamin $C$ and $E$ on cypermethrin -induced changes in cardiac ALP, LDH and GGT activites in female wistar rats

Cypermethrin significantly altered in cardiac ALP, LDH and GGT activities in the exposed rats when compared to control, administration of vitamins $\mathrm{C}$ and $\mathrm{E}$ significantly altered these results (Figure 2).

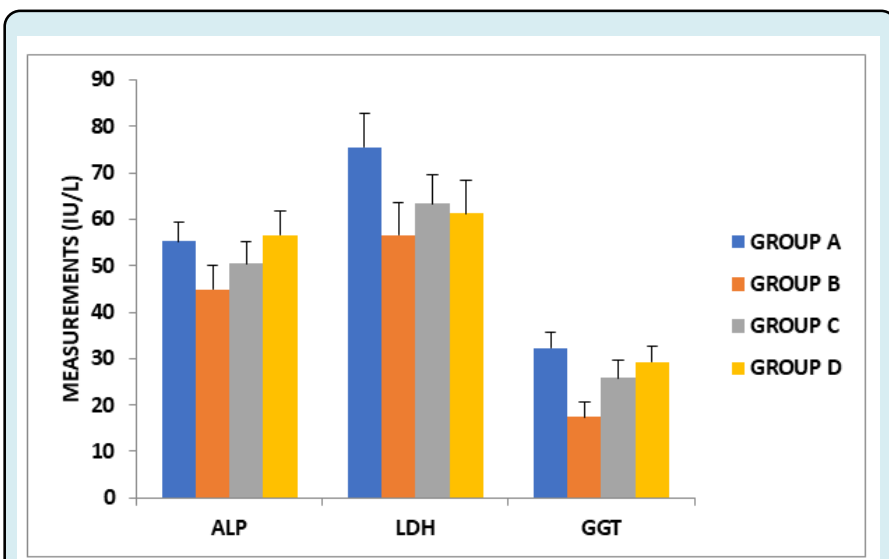

Figure 2: The effect of administration of vitamin $C$ and $\mathrm{E}$ on cypermethrin -induced changes in cardiac ALP, LDH and GGT in female wistar rats.

Values are means \pm SD.

The effect of administration of vitamin C and $E$ on cypermethrin -induced changes in hepatic lbumin, globulin and total protein concentrations in female wistar rats in serum biocarbonate and sodium ion concentrations in female wistar rats

Cypermethrin resulted in significant increase in serum cardiac albumin, globulin and total protein concentrations biocarbonate and sodium ion concentrations in the exposed rats when compared to control. Exposure of these rats individually to vitamins $\mathrm{C}$ and $\mathrm{E}$ significantly modulated the concentration of these ions (Figure 3).

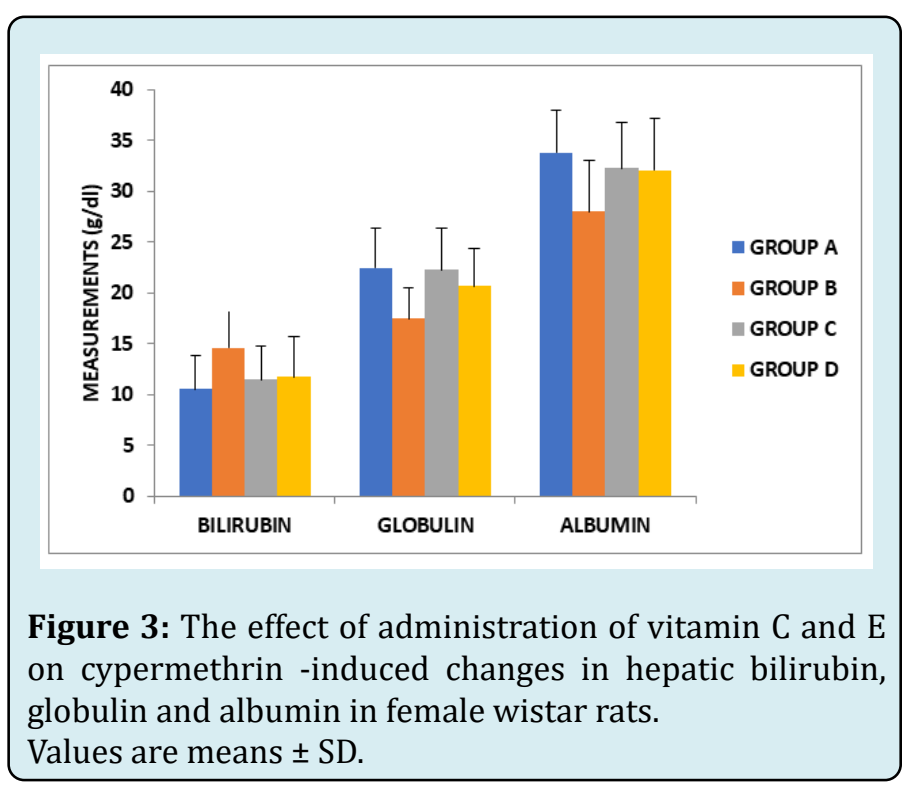


The effect of administration of vitamin $C$ and $E$ on cypermethrin -induced changes in the activites of serum AST and ALT in female wistar rats
Activities of AST and ALT were significantly induced in the rats exposed to cypermethrin when compared to control, however, administration of vitamins $\mathrm{C}$ and $\mathrm{E}$ significantly modulated these activities (Figure 4).

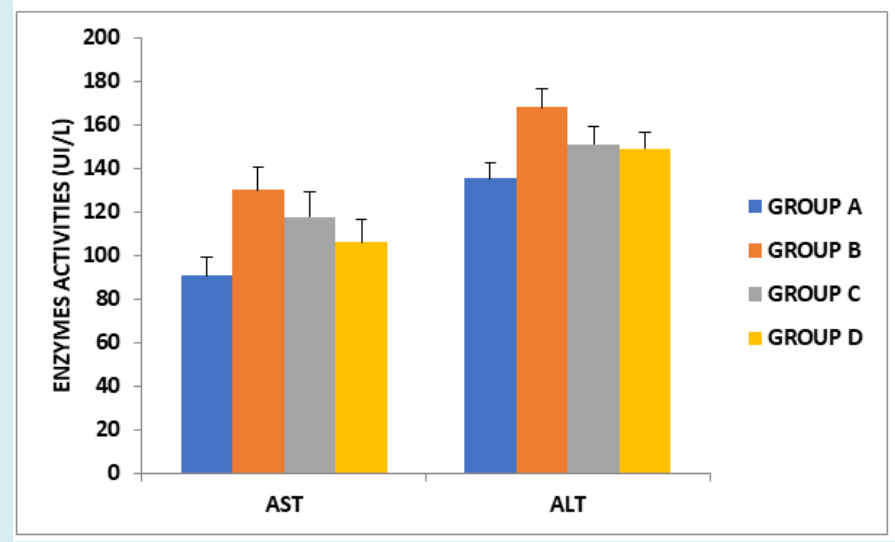

Figure 4: The effect of administration of vitamin $\mathrm{C}$ and $\mathrm{E}$ on cypermethrin -induced changes in serum AST and ALT in female wistar rats.

Values are means \pm SD.
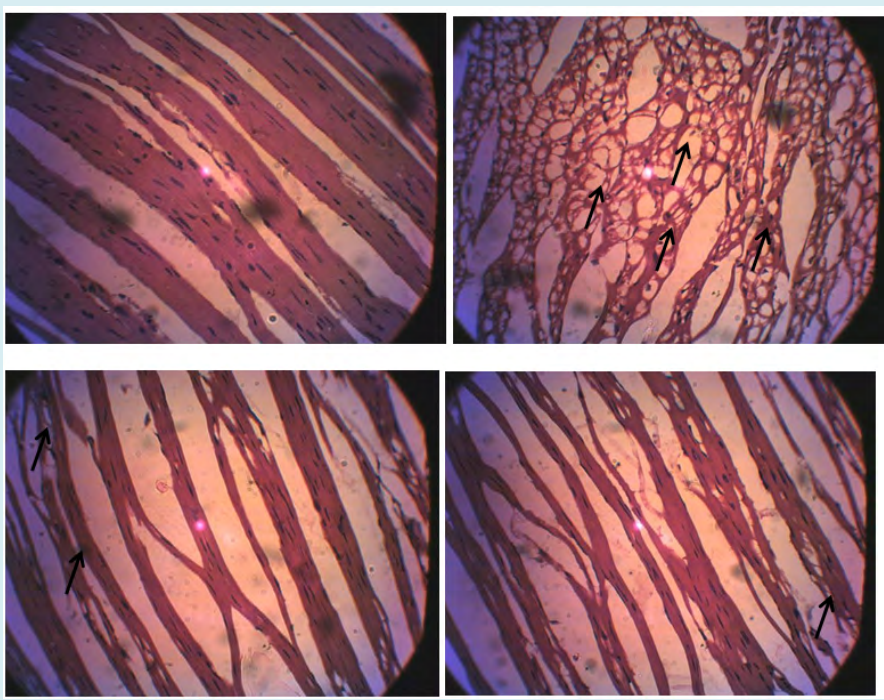

Figure 5: Photomicrograghs of section of cardiac tissues of rats administered Cypermethrin, vitamin C and E.

A: control rats showing normal cardiac muscle fiber architecture with multiple elongated nuclei. The cardiac muscles are branched with less space between the muscle fibers.

B: rats administered cypermethrin only showing damage histo architecture of the cardiac muscle characterized by severe vacuolization of cardiac muscle with no clear branching.

C: rats administered cypermethrin + Vitamin C showing a fairly normal cardiac muscle branched and multinucleated. Areas of mild vacuolization are seen and enlarge intramuscular fiber space.

D: rats administered cypermethrin + Vitamin E showing mild vacuolization and enlarged intramuscular fiber space. Cardiac muscle branched and multinucleated. 

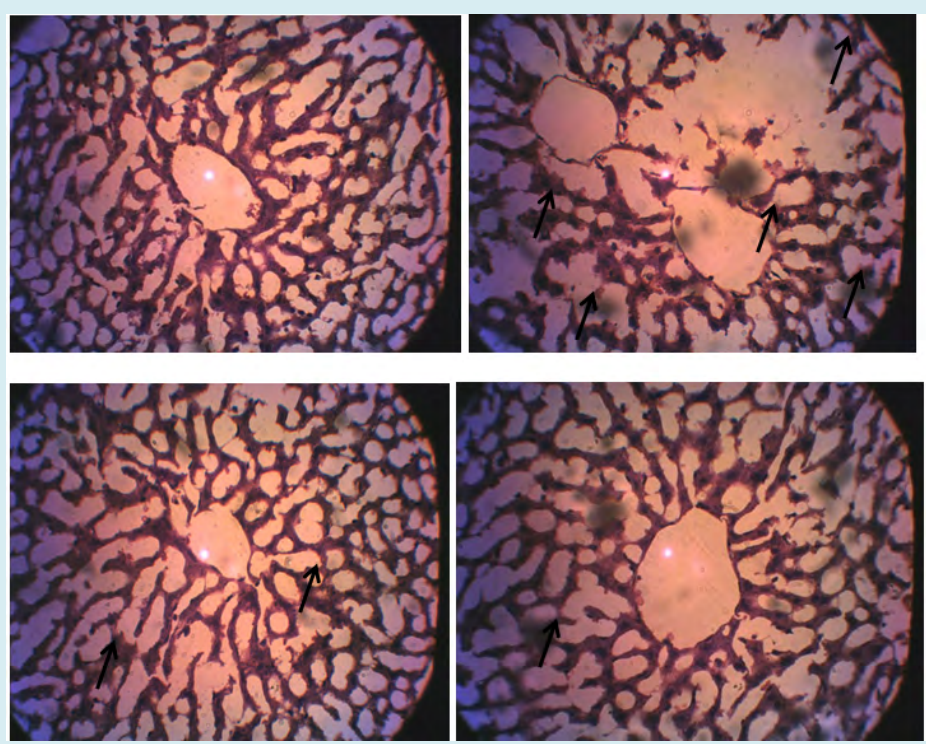

Figure 6: Photomicrograghs of section of hepatic tissues of rats administered Cypermethrin, vitamin C and E.

A: control rats showing normal hepatic architecture, moderately arranged in a cord like manner radiating from the central vein and separated by an irregular and widen sinusoid

B: rats administered cypermethrin only showing severe damage hepatic histo-architecture characterized by damage liver parenchyma and hepatocyte. The hepatocytes are scattered in the hepatic parenchyma instead of radiating in a cord arrangement from the central vein and are separated by a widening sinusoid.

C: rats administered cypermethrin + Vitamin C showing moderately arranged in a cord like manner radiating from the central vein and separated by an irregular and widen sinusoid with mild degeneration of hepatocytes.

D: rats administered cypermethrin + Vitamin E showing mild degeneration of hepatocytes

\section{Discussions}

Biochemical parameters are sensitive index to determine the changes in the body system due to exposure to pesticide toxicity and can constitute important tools in toxicological studies [15]. Therefore, the purpose of this work is to evaluate the effect of cypermethrin on some selected biochemical parameters. Result showed that albumin, globulin, and total protein significantly $(\mathrm{P}<0.05)$ decreased in heart and liver of the rats administrated cypermethrin alone. The decrease in the concentrations of these parameters could be attributed to necrosis of the heart and liver by the toxicant which leads to the impairment in the metabolism of these parameters [16]. This result is in tandem with the previous report of Ojutiku, et al [17]. However, treatment with vitamin C and E significantly attenuated the toxic effects of the toxicant. Vitamins C and E individually have been reported for their abilities to ameliorate pathological changes in serum proteins associated with diseased conditions [18-20].

The observed significant decrease in the activities of enzymes (ALP, LDH and GGT) in the heart of rats administered cypermethrin is suggestive of cardiac tissues damage. Enzyme activities in tissues are often used as marker to ascertain early toxic effects of administered foreign compounds to experimental animals $[21,22]$. Decrease of these enzymes in the organs such as heart might be due to possible membrane damage or due to stress condition resulting into leakage of the enzymes from the heart into the serum. ALP is a marker enzyme for plasma membrane and is required for proper functioning of organs. LDH is an intracellular enzyme present in nearly all metabolizing cells with highest concentration in the heart, skeletal muscle and erythrocytes.

Activities of ALT and AST are routinely measured clinically as diagnostic tools in assessment of hepatocellular injury and health status of the liver [22,23]. Result of this study revealed that administration of Cypermethrin in rats caused a significant increase $(\mathrm{P}<0.005)$ in serum concentrations of ALT and AST. This is an indication that Cypermethrin might have caused alteration in biochemical activities in liver and also compromised the integrity of the membrane causing the release of these enzymes into the blood stream. However, treatment with vitamin $\mathrm{C}$ and $\mathrm{E}$ significantly reverse these alterations.

Photomicrograph of the heart and liver of rats administered cypermethrin show significant histological 
distortions in their normal appearance and architecture. The cardiac tissues were characterized by severe vacuolization, deformed nuclei, disarray of myofibres and connective tissue deposits which might probably be due to degeneration of the structural protein in mitochondria of the cytoplasm. The livers of cypermethrin treated rats also indicate acute tubular necrosis, damaged parenchyma and vascular congested cells with degenerated tubules. The hepatocytes were scattered in the hepatic parenchyma instead of radiating in a cord arrangement from the central vein and are separated by a widening sinusoid. These alterations were found to be reduced following the administration of vitamin $\mathrm{C}$ and $\mathrm{E}$.

\section{References}

1. Bernet D, Schmidt H, Meier W, Burkhardt-Holm P, Wahli $T$ (1999) Histopathology in fish: roposal for a protocol to assess aquatic pollution. J Fish Dis 22(1): 25-34.

2. Clark JM, Brooks MW (1989) Neurotoxicology of pyrethroids: single or multiple mechanisms of action? Environ Toxicol Chem 8: 361.

3. Abbassy MA, Eldefrawi ME, Eldefrawi AT (1983) Pyrethroid action on the nicotinic acetylcholine receptor / channel, Pesticide Biochem Physio 19(3): 299.

4. Amano S, Ohashi M, Kirihara M, Yang XH, Hazama $\mathrm{F}$ (1994) Alpha-tocopherol protects against radicalinduced injury in cultured neurons. Neurosci Lett 170(1): 55-58.

5. Butterfield DA, Castegna A, Drake J, Scapagnini G, Calabrese V (2002) Vitamin E and neurodegenerative disorders associated with oxidative stress. Nutr Neurosci 5(4): 229-239.

6. Peyser CE, Folstein M, Chase GA, Starkstein S, Brandt J, et al. (1995) Trial of D-alpha-tocopherol in Huntington's disease. Am J Psychiatry 152(2): 1771-1775.

7. Traber MG, Stevens JF, Stevens (2011) Free Radical Biology and Medicine-Vitamins C and E: Beneficial effects from a mechanistic perspective. Free Radical Biology and Medicine 51(5): 1000-1013.

8. National Research Council (NRC) (2011) Guide for the care and use of laboratory animals 8th Edition. The National Academies Press.

9. Lowry OH, Rosebrough NJ, Farr AL, Randall RJ (1951) Protein measurement with the Folin phenol reagent. J Biol Chem 193(1): 265-275.

10. Mokady IC, Abramovici A, Cogan U (1989) The safety evaluation of dunaviela bardawilla as a potential food supplements. Food and Chemical Toxicology 27: 221226.

11. Tietz NW, Pruden EL, Siggaard-Anderson O (1994) In: Tietz textbook of Clinical Chemistry. Burtis CA, Ashwell ER (Eds.) WB Saunder Co. London, pp: 1354-1374.

12. Reitman S, Frankel S (1957) A colorimetric method for the determination of serum glutamic oxaloacetate aminotransferase. Am J Clin Pathol 28(1): 56-63.

13. Wright PJ, Plummer DT, Leathwood PT (1972) Enzyme in rat urine. Alkaline phosphatase. Enzymologia 42(4): 317-327.

14. Vanderlinde RE (1985) Measurement of total lactate dehydrogenase activities. Annals of Clinical Lab Sci 15(1): 13-31.

15. Siddiqui MA (2004) Toxicological and immunological studies of sub-acute exposure of Cockerels Imidacloprid and Quinalphos.M.V.Sc. Thesis submitted to Gujarat Agricultural University. Anand, India, pp: 18-120.

16. Oladele J0, Adewale 00, Oyewole OI, Gbolagbade A, Oyeleke MO (2020) Assessment of the Protective Effects of Vitamin C and E on Cypermethrin-induced Nephrotoxicity and Electrolyte Imbalance in Wistar Rats. Journal of basic and applied Research in Biomedicine 6(1): 1-6

17. Ojutiku RO, Asuwaju FP, Ayanda IO, Obande RA, Agbelege OO (2013) Effect of Acute Toxicity of Cypermethrin on Some biochemical Parameters of Juveniles of Claria Gariepinus. (Burchell, 1822). International Journal of Engineering Science Invention 2(3): 01-07

18. Edoga CO, Njoku 00, Okeke JJ, Ani CE (2013) Effect of vitamin c treatment on serum protein, albumin, betaglobulin profiles and body weight of Trypanosoma brucei-INFECTED Rattus norvegicus. Animal Research International 10(1): 1685.

19. Diab AA, Zahra MH, Hendawy AA, Hamza RZ, Mekky GA (2014) Hepatoprotective Effect of Curcumin and Vitamin $\mathrm{C}$ against Cisplatin Induced Oxidative Stress and Toxicity in Albino Rats. Journal of American Science 10(11): 3748.

20. Akhtar MS, Pal AK, Sahu NP, Ciji A (2013) Hematoimmunological responses of Labeo rohita juveniles to temperature and salinity stress: effect of dietary L-tryptophan. Isr J Aquac 65: 1-8.

21. Adesokan AA, Akanji MA (2004) Effect of administration of aqueous extract of Enantia chlorantha on the activities 
of some enzymes in the small intestine of rats. Nig J Biochem Mol Biol 18: 103-105.

22. Oyewole OI, Oladele JO (2017) Changes in activities of tissues enzymes in rats administered Ficus exasperata leaf extract. Int J Biol Chem Sci 11(1): 378-386.
23. Omeodu SI, Monanu M, Anosike EO (2008) Effect of aqueous extract of African mistletoe (Tapinanthus bangwesis) on some serum enzymes of rats with carbon tetrachloride- induced liver damage. Int J Biol Chem Sci 2(4): 448-455. 